\title{
Gravity wave amplification and phase crest re-organization over a shoal
}

\author{
N. Jarry ${ }^{1,2}$, V. Rey $^{1}$, F. Gouaud ${ }^{1}$, and D. Lajoie ${ }^{2}$ \\ ${ }^{1}$ LSEET, Université du Sud Toulon-Var, B.P 20132 F8395, la Garde, Cedex, France \\ ${ }^{2}$ ACRI-in, 06904 Sophia-Antipolis Cedex, France
}

Received: 15 September 2010 - Accepted: 24 October 2010 - Published: 14 March 2011

\begin{abstract}
In this experimental work, both wave amplification and phase evolution, due to a submerged mound, are studied. In addition to the classical surface wave measurements, the experimental study takes advantage of photographs that underline crest re-organization above and down-wave the shoal. In particular, together with wave amplification up to more than twice the incident wave, a wave steepening is observed in certain conditions in both the wave direction and in the cross-section. Due to a phase crest separation downstream of the shoal, steepening in the crossshore direction is enhanced (up to $30 \%$ above the steepening along the main direction of propagation). Physical aspects are discussed through the analysis of the diffraction effects on the wave properties.
\end{abstract}

\section{Introduction}

An estimate of the wave characteristics near the shore has been one of the major issues in coastal engineering. For the purpose of the maritime navigation, the local increase of wave steepness may become dramatic when huge waves are generated. For wave propagating over varying sea-bed topography, wave propagation numerical models, that are spectral (Booij et al., 1999; Benoit et al., 1996), phase resolving (Berkhoff, 1972; Radder, 1979; Kirby, 1986) or based on Boussinesq equations ( $\mathrm{Li}$ and Zhan, 2001) have been developed. For their validation, comparisons to experimental studies are often made. A number of experiments on different shoal configurations with various shapes were realised (Arthur, 1946; Berkhoff et al., 1982; Vincent and Briggs, 1989) in order to determine the wave transformation behind the shoal. Numerous numerical

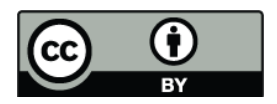

Correspondence to: V. Rey

(rey@univ-tln.fr) models were tested on the Vincent and Briggs' experiment conducted in CERC's basin (e.g., Suh and Dalrymple, 1993; Holthuijsen et al., 2003). The shoal consisted of an elliptic mound, patterned after Berkhoff et al. (1982), with a major radius of $3.96 \mathrm{~m}$, minor radius of $3.05 \mathrm{~m}$, and a maximum height of $30.48 \mathrm{~cm}$ at the centre, on which monochromatic and spectral incident waves were tested. They showed, in particular, wave amplification up to more than twice that of the incident wave at the downstream part of a submerged elliptical mound for regular waves. As a consequence, wave steepness is strongly increased since the wave length is shorter above the mound. If wave amplification and direction of propagation are well-illustrated in these studies, there is no information on the wave phase evolution, especially in the cross-shore direction. This can be of major interest since wave diffraction may lead to steep slopes along the crests. The purpose of this work is to study both wave amplification and phase evolution due to a submerged mound. In addition to the classical surface wave measurements, the experimental study takes advantage of photographs that underline crest reorganization above the shoal. After a presentation of the experimental set-up, results are presented and discussed.

\section{Experimental set-up}

The experiment was performed at the wave basin of Toulon University, France. The basin has a useful length of $10 \mathrm{~m}$, an effective width of $2.6 \mathrm{~m}$ and a maximum water depth of about $1 \mathrm{~m}$. At one end, a wave generator allowed to generate regular and unidirectional waves. At the other end, a parabolic duckboard played an absorber function. The underwater three-dimensional mound is a $1.50 \mathrm{~m}$ long by $1 \mathrm{~m}$ wide quasi-elliptic shoal, with a maximum height of $30 \mathrm{~cm}$ as shown in Fig. 1. It consisted of a half-sphere, widened with a $50 \mathrm{~cm}$ rectilinear part on its centre. The extension of the shoal in the wave propagation direction ( $\mathrm{x}$-axis) had been numerically tested by using the model REF/DIF1 (Kirby

Published by Copernicus Publications on behalf of the European Geosciences Union. 


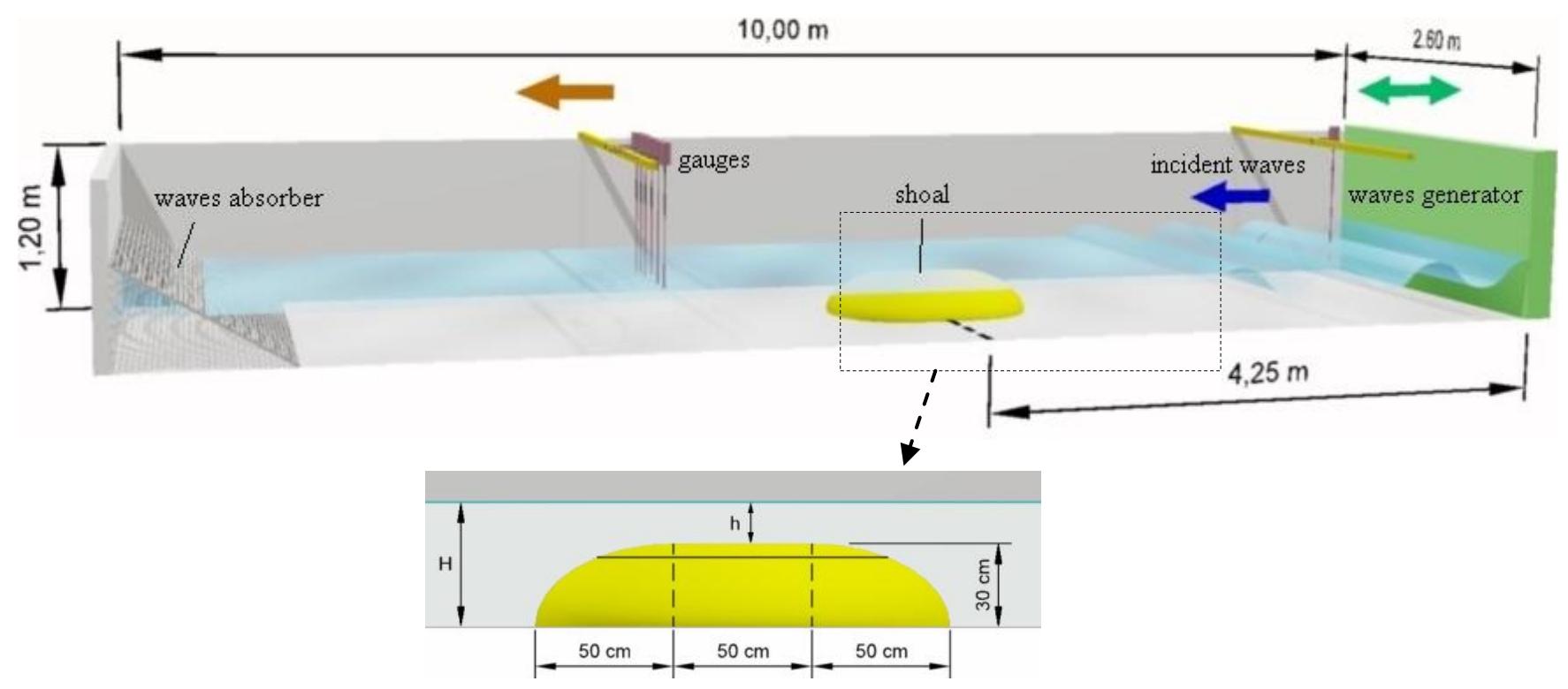

Fig. 1. Experimental set-up.

et al., 2002) during a dimensioning phase to increase the wave amplification, and to offer a longer part on which the waves were refracted. The centre of the shoal was located at $\mathrm{x}=4.25 \mathrm{~m}$ from the wave generator, length wise, It is centred in the middle of the basin $(y=2 \mathrm{~m})$, width wise.

For the wave measurements, a resistive wave gauge was placed in front of the wave generator as reference, and 6 others were fixed linearly crosswise on a mobile girder. In Fig. 2, the location of the shoal and of the gauges are presented from a plan view. Gauges 2-4 were separated from a distance of $15 \mathrm{~cm}$ whereas gauges 4-7 were spaced by $20 \mathrm{~cm}$, in order to improve the accuracy of the measure just above the shoal.

Acquisition was done through the mobile girder every $10 \mathrm{~cm}$, from $0.30 \mathrm{~m}$ upstream the shoal $(\mathrm{x}=3.20 \mathrm{~m})$ to $1.40 \mathrm{~m}$ downstream $(x=6.40 \mathrm{~m})$. The sampling frequency was $32 \mathrm{~Hz}$, the duration of the data acquisition was $60 \mathrm{~s}$. A digital camera was placed on a footbridge at $8 \mathrm{~m}$ from the wave generator. Photographs were shot at $1 \mathrm{~m}$ and $2 \mathrm{~m}$ above the water level in the total dark.

The only light came from the flash of the camera that lit the basin in an oblique way. This allowed crests to be illuminated and easily distinguishable on the photographs. In the experiment, incident waves are monochromatic and unidirectional. A summary of all the experimental conditions is provided in Table 1. In the present study focused on wave steepening due to refraction-diffraction over the shoal, runs $6-8$ are analysed (water depth $h=0.05 \mathrm{~m}$ above the top of the shoal). Runs at this water level for higher wave heights (runs 9-12) did not show any significant changes in the free surface behaviours, except a slight breaking for the highest periods that disturbed observations of the crests location. Detailed results for the other cases are presented

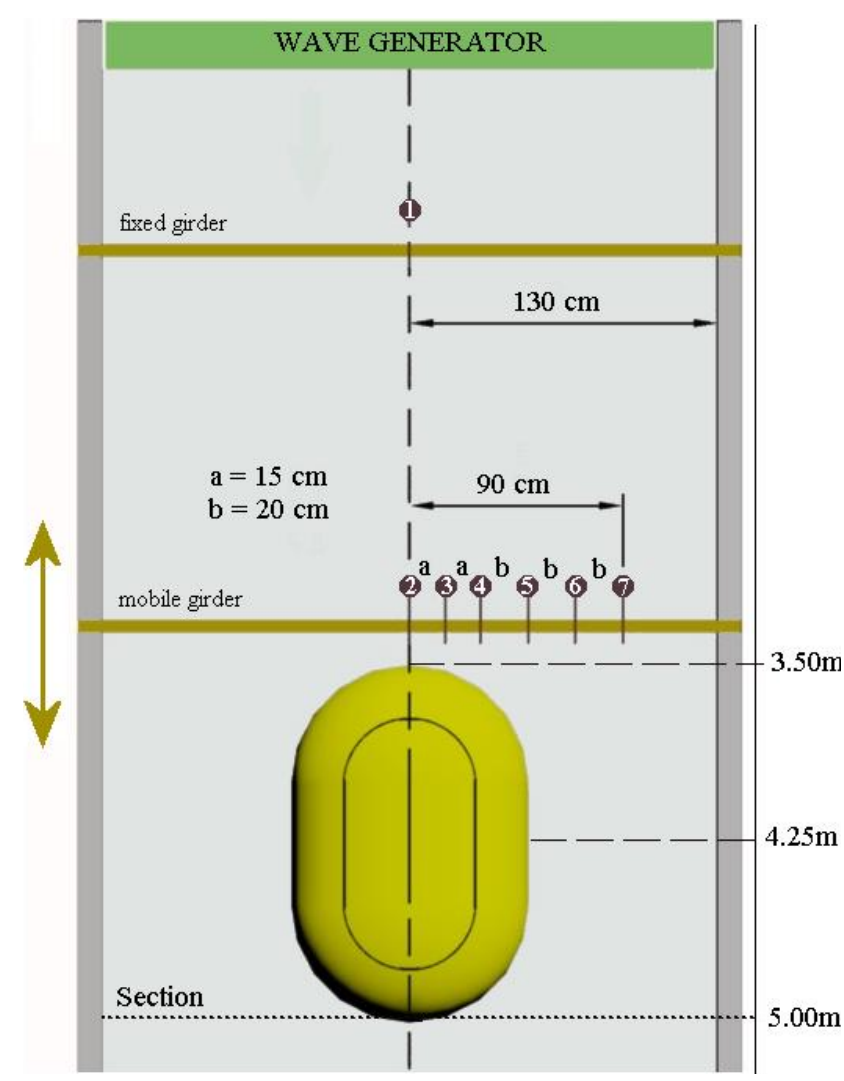

Fig. 2. Schematic plan view of the shoal and location of the wave gauges.

in Jarry (2009). They underline the diffraction phenomenon for the submerged cases and the freely wave crests crossing when the shoal is emerged. 
Table 1. Experimental wave characteristics.

\begin{tabular}{lccccc}
\hline Test & $\begin{array}{c}\text { Water depth above the top } \\
\text { of the mound } h \\
(\mathrm{~cm})\end{array}$ & $\begin{array}{c}\text { Wave amplitude } \\
A=H / 2 \\
(\mathrm{~cm})\end{array}$ & $\begin{array}{c}\text { Wave period } \\
(\mathrm{s})\end{array}$ & $\begin{array}{c}\text { Wave length in } \\
\text { deep water } \lambda \\
(\mathrm{cm})\end{array}$ & $\begin{array}{c}\text { Steepness } \\
\xi=H / L\end{array}$ \\
& 10 & 0.5 & 0.3 & 14 & 7.1 \\
\hline Run 1 & 10 & 0.5 & 0.4 & 25 & 4.0 \\
Run 2 & 10 & 0.5 & 0.5 & 39 & 2.6 \\
Run 3 & 10 & 0.5 & 0.6 & 56 & 1.8 \\
Run 4 & 5 & 0.5 & 0.3 & 14 & 7.1 \\
Run 5 & 5 & 0.5 & 0.4 & 25 & 4.0 \\
Run 6 & 5 & 0.5 & 0.5 & 39 & 2.6 \\
Run 7 & 5 & 0.5 & 0.6 & 56 & 1.8 \\
Run 8 & 5 & 0.7 & 0.3 & 14 & 10.0 \\
Run 9 & 5 & 0.7 & 0.4 & 25 & 5.6 \\
Run 10 & 5 & 0.7 & 0.5 & 39 & 3.6 \\
Run 11 & 5 & 0.7 & 0.6 & 56 & 2.5 \\
Run 12 & -15 & 0.5 & 0.3 & 14 & 7.1 \\
Run 13 & -15 & 0.5 & 0.4 & 25 & 4.0 \\
Run 14 & -15 & 0.5 & 0.5 & 39 & 2.6 \\
Run 15 & -15 & 0.5 & 0.6 & 56 & 1.8 \\
Run 16 & & & & & \\
\hline
\end{tabular}

\section{Experimental results}

The experimental results, hereafter presented, correspond to runs 6 to 8 . They correspond to the moderate incident wave steepness $\xi=H / L$ and to a water depth $h=0.05 \mathrm{~m}$ above the top of the shoal (see Table 1).

\subsection{Wave evolution in the direction of propagation}

The amplification factor along $\mathrm{x}$-axis in the centre of the wave basin $(\mathrm{Y}=2 \mathrm{~m})$ is presented in Fig. 3, respectively, for $T=0.4 \mathrm{~s}, 0.5 \mathrm{~s}$ and $0.6 \mathrm{~s}$. The same trend is observed, with an increase of the amplitude up to $X=4.5-4.7 \mathrm{~m}$, near the end of the top part of the shoal (see Table 2) and a decrease downstream.

For $T=0.6 \mathrm{~s}$, an increase of a factor 2.5 of the wave amplitude is observed. The relative wave slope RWS can be calculated as follows:

$\mathrm{RWS}=\frac{H}{H_{0}} \frac{L_{0}}{L}$

Where $H_{0}$ and $L_{0}$ are, respectively, the incident wave height and wave length, $H$ is the maximum wave height and $L$ the local distance between two successive maxima. RWS for runs 6-8 are reported in Table 2. We can observe (see Sect. 3.2) that the local distance between two successive maxima downstream the shoal is slightly higher than for the incident wave. It can be explained by the wave diffraction phenomenon at the origin at the wave acceleration in the central part of the shoal (see Sect. 4.1).

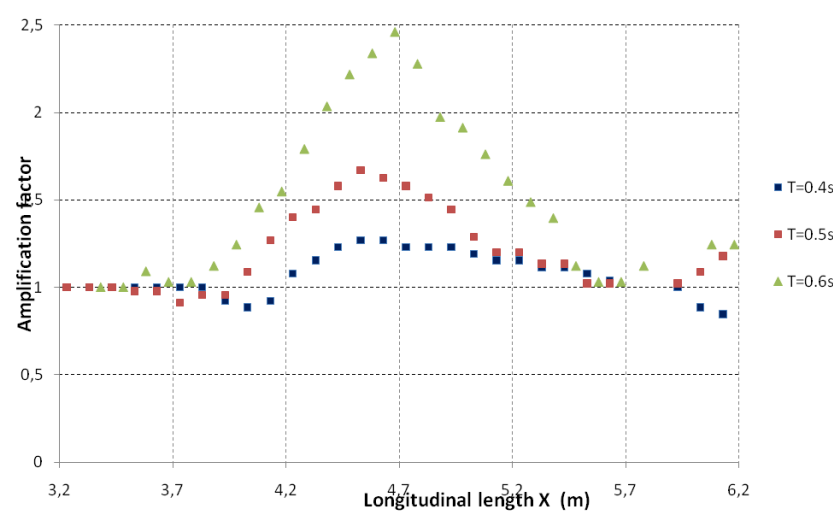

Fig. 3. Amplification factor along $x$-axis in the centre of the basin.

Table 2. Maximum amplification factor and wave slope along the $\mathrm{x}$-axis.

\begin{tabular}{lllll}
\hline Run & Period & $\begin{array}{l}\text { Maximum } \\
\text { amplification }\end{array}$ & $\begin{array}{l}\text { Distance from } \\
\text { the wavemaker } \\
\mathrm{x}(\mathrm{m})\end{array}$ & $\begin{array}{l}\text { Relative } \\
\text { wave } \\
\text { slope }\end{array}$ \\
\hline 6 & $T=0.4$ & 1.40 & 4.80 & 1.07 \\
7 & $T=0.5$ & 1.75 & 4.70 & 1.67 \\
8 & $T=0.6$ & 2.50 & 4.70 & 2.22 \\
\hline
\end{tabular}




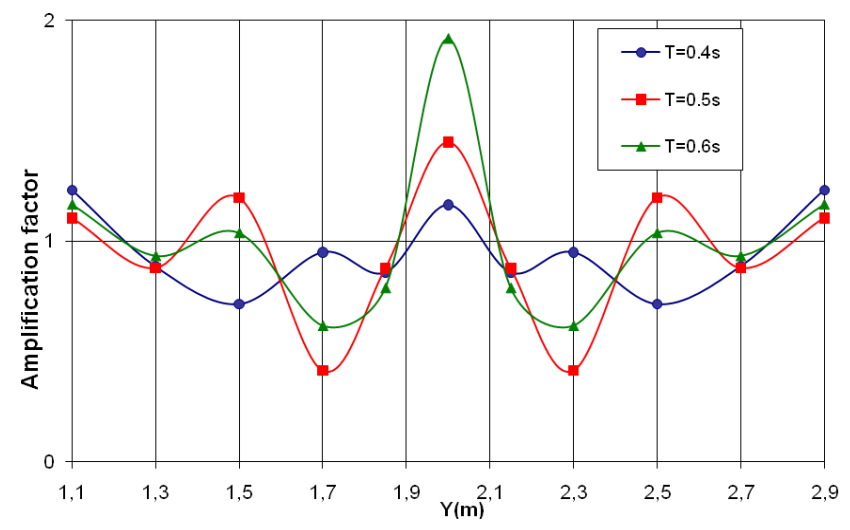

Fig. 4. Amplification factor in the cross-section $\mathrm{x}=5 \mathrm{~m}$ downstream of the shoal.

Table 3. Wave slopes along the y-axis.

\begin{tabular}{lcc}
\hline Run & Period & Relative wave slope \\
\hline 6 & $T=0.4$ & 0.25 \\
7 & $T=0.5$ & 0.73 \\
8 & $T=0.6$ & 1.21 \\
\hline
\end{tabular}

\subsection{Wave amplitude evolution in a cross-section}

The amplification factor along y-axis down-wave the shoal $(\mathrm{X}=5 \mathrm{~m})$ is presented in Fig. 4 for $T=0.4,0.5$ and $0.6 \mathrm{~s}$.

We can observe an oscillating behaviour of the amplification with decreasing values of the maxima from the centre to the sides of the wave basin. Assuming an almost constant phase in the cross-section, the maximum slope is given by $\Delta H / L_{\mathrm{c}}$ where $\Delta H$ is the difference between the maximum (at $\mathrm{Y}=\mathrm{Y}_{\max }=2$ ) and the first minimum (at $\mathrm{Y}=\mathrm{Y}_{\min }$ ) and $L_{\mathrm{c}}=\mathrm{Y}_{\min }-\mathrm{Y}_{\max }$. The RSW can be expressed as follow:

$\mathrm{RWS}=0.5 \frac{\Delta H}{H_{0}} \frac{L_{0}}{L_{\mathrm{c}}}$

Results are given in Table 3.

We can see that the wave slope remains quite mild compared to the wave slope in the direction of propagation.

\subsection{Wave crests evolution}

Photographs of the free surface for runs 6 to 8 are presented in Figs. 5-7.

As a general trend, we can observe a refraction-diffraction process due to the shoal. Downstream of the shoal, a tridimensional pattern is observed due to segmentation onto 3 parts of the wave crest: a central crest with a quasilinear increase of its width and two symmetrical crests of an opposite phase on both sides. The quantitative results are calculated thanks to the synchronized wave gauges $2-7$ and

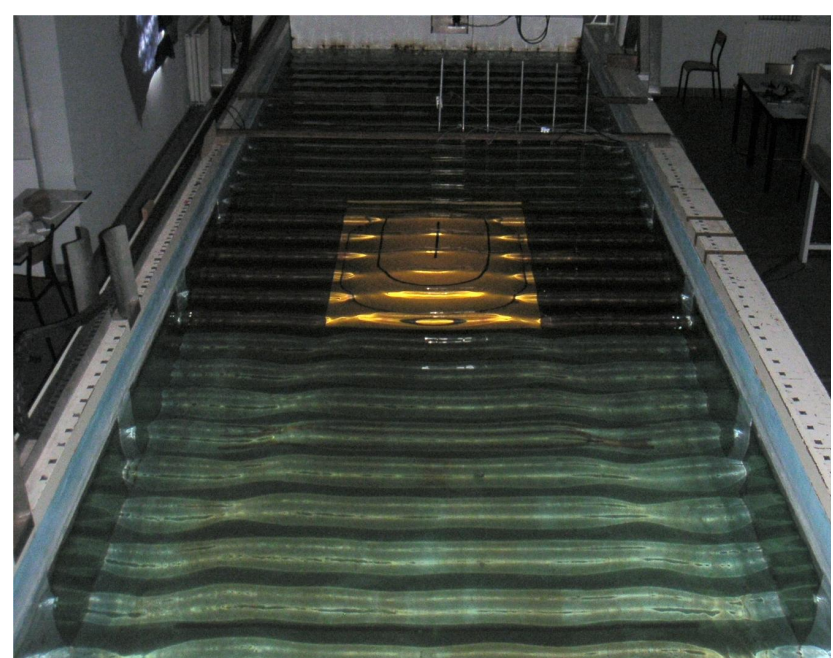

Fig. 5. Photograph of the free surface for run $6, T=0.4 \mathrm{~s}$

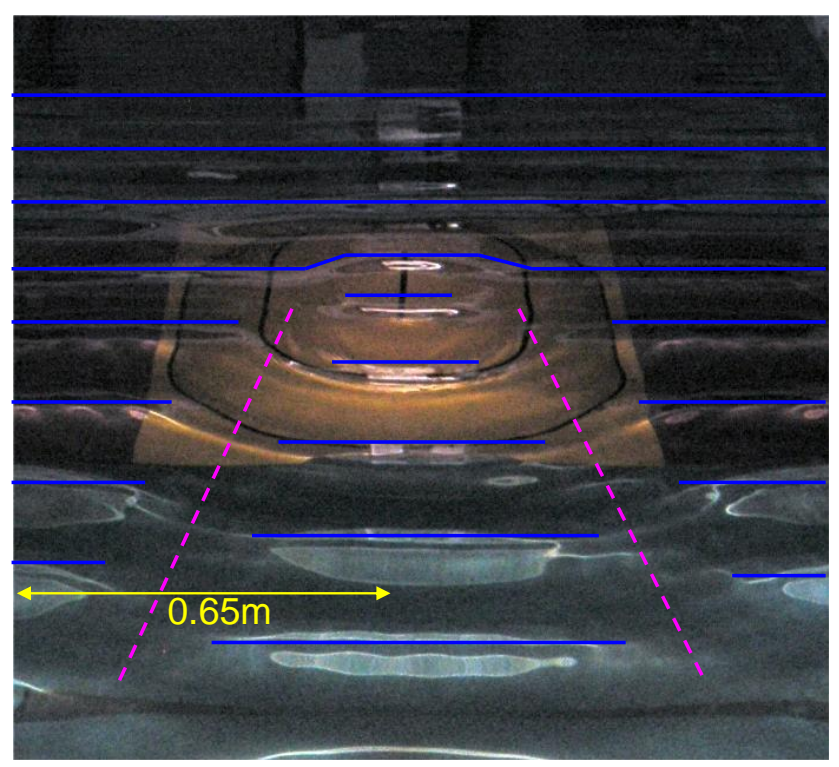

Fig. 6. Photograph of the free surface for run $7, T=0.5 \mathrm{~s}$.

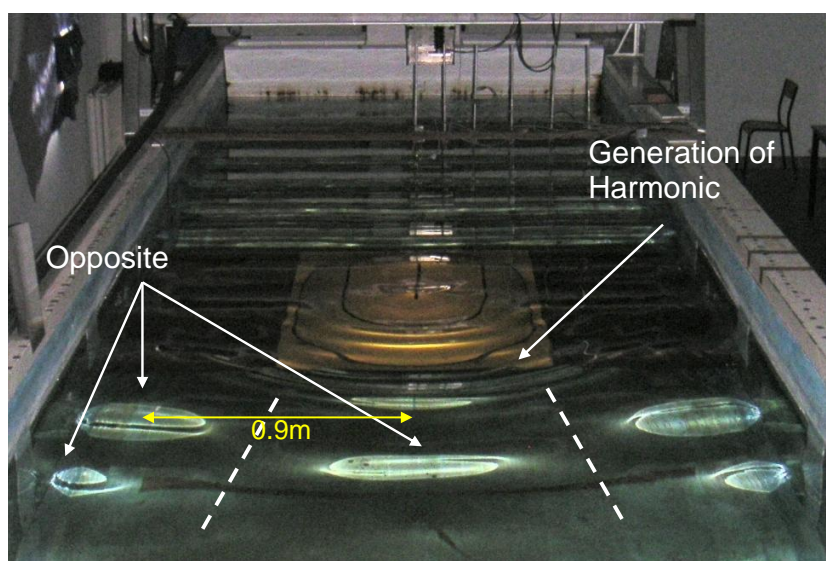

Fig. 7. Photograph of the free surface for run $8, T=0.6 \mathrm{~s}$. 

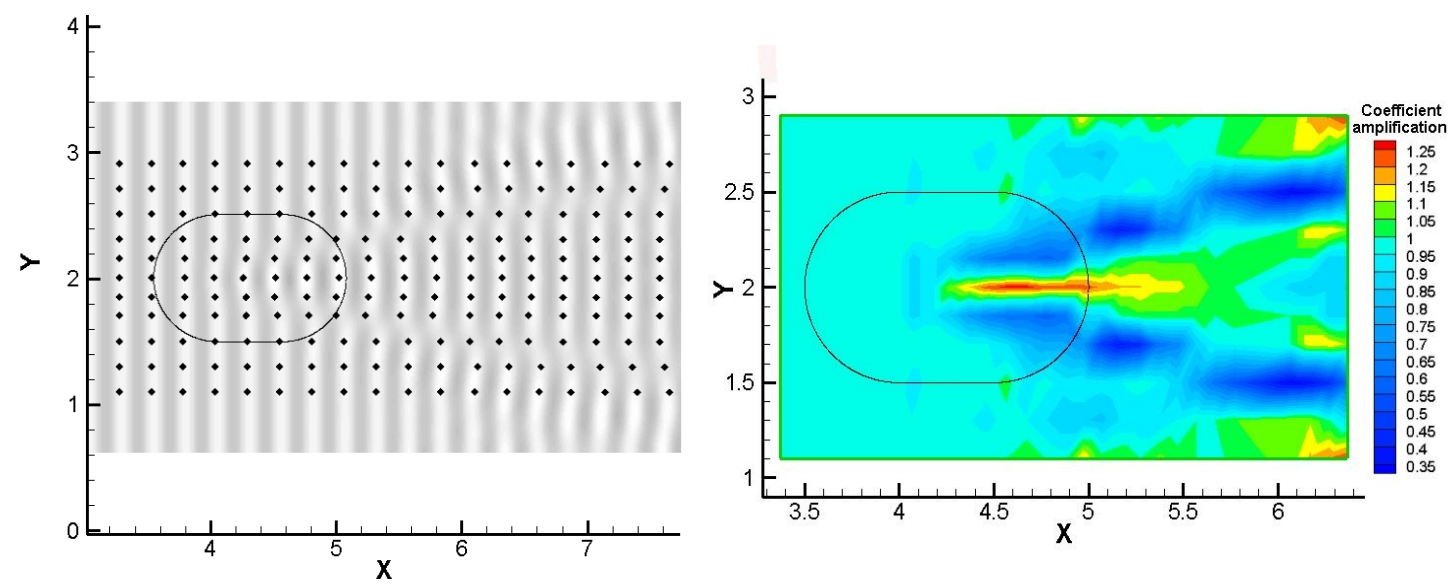

Fig. 8. Wave phase (left) and amplitude (right) measurements, $T=0.4 \mathrm{~s}$.
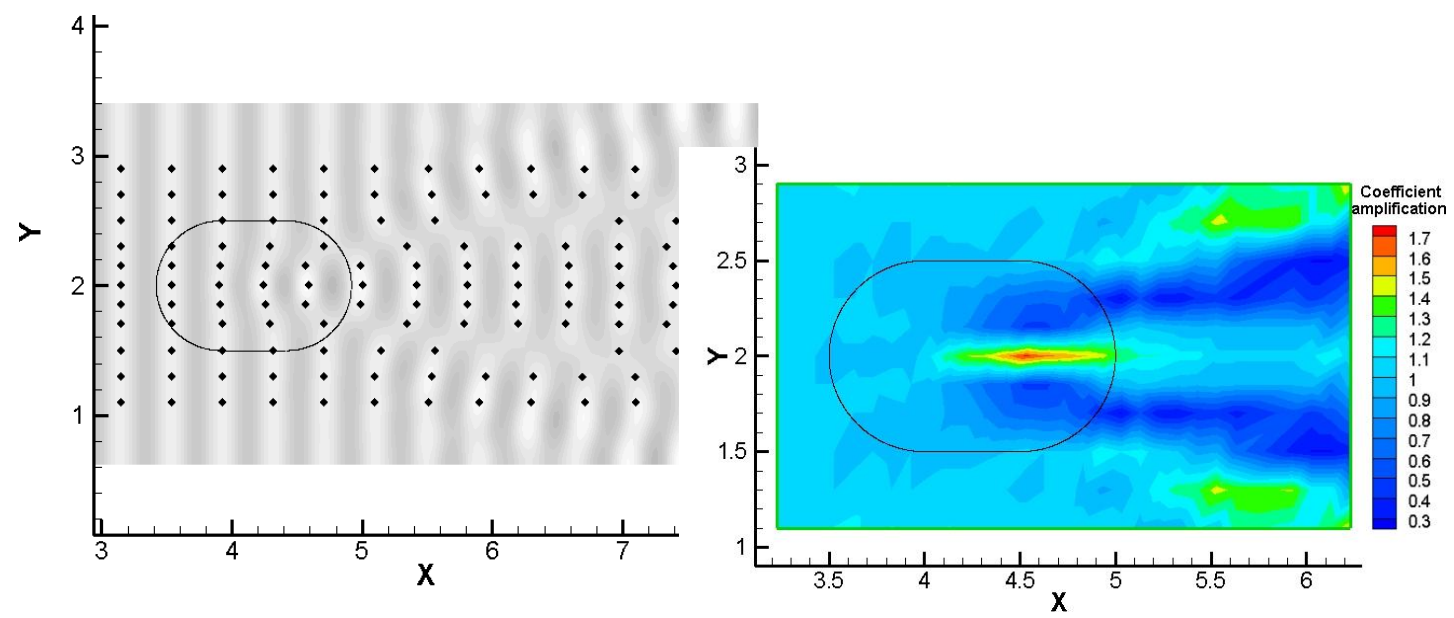

Fig. 9. Wave phase (left) and amplitude (right) measurements, $T=0.5 \mathrm{~s}$.

the use of the gauge 1 as a reference for successive locations of the girder along the basin. Wave phases along the basin (diamonds, crest extrapolations are in grey) and amplitudes above and after the shoal are presented in Figs. 8-10 for runs 6-8.

In Figs. 5-7, the boundary between the crest at the centre and on both sides is depicted by two dotted lines moving apart with a certain angle. This opening angle is logically due to a diffraction effect since refraction does not occur after the shoal passage, because of a flat bottom. The phase lag between the crest at the centre of the basin and the crest on both sides is about one half-period, as observed in Figs. 8-10. Within this transitional zone, the signal from the wave gauges was completely flat and then did not allow the determination of the location of the crests. Let us note that for the run $8(T=0.6 \mathrm{~s})$, the basin was quickly subject to transverse oscillations that disturbed wave propagation.

However, for the three cases, both photographs and wave fields show that despite the phase lag at the crests in the cross direction, a behaviour of the crests nearly rectilinear is observed down-wave of the shoal. For $T=0.4 \mathrm{~s}$ (Figs. 5 and 8), the central crest is rectilinear with an almost constant amplitude in the cross direction after down-wave from the shoal after a transition zone diffusion of the energy along the crests (see the three first wavelengths in Fig. 10). We can also observe a diminishing of the phase lag (from $X=5.8 \mathrm{~m}$ ), which may also be due to sidewall effects. Similar trends are observed for $T=0.5 \mathrm{~s}$ and $T=0.6 \mathrm{~s}$ with a more pronounced curvature of the crests.

Right downstream $(X=5 \mathrm{~m})$, central and side lines are in opposite phases. The maximum slope is then given by $\Delta H / L_{\mathrm{c}}$ where $\Delta H$ is the sum of the maximum (at $\mathrm{Y}=\mathrm{Y}_{\max }=2$ ) and the first minimum (at $\mathrm{Y}=\mathrm{Y}_{\min }$ ) and $L_{\mathrm{c}}=\mathrm{Y}_{\min }-\mathrm{Y}_{\max }$. The RSW are given by expression (2), results are presented in Table 4.

We can observe that the wave slope is of the same order as observed in the direction of propagation. For $T=0.6 \mathrm{~s}$, the slope is $30 \%$ steeper than observed in the direction of propagation. 

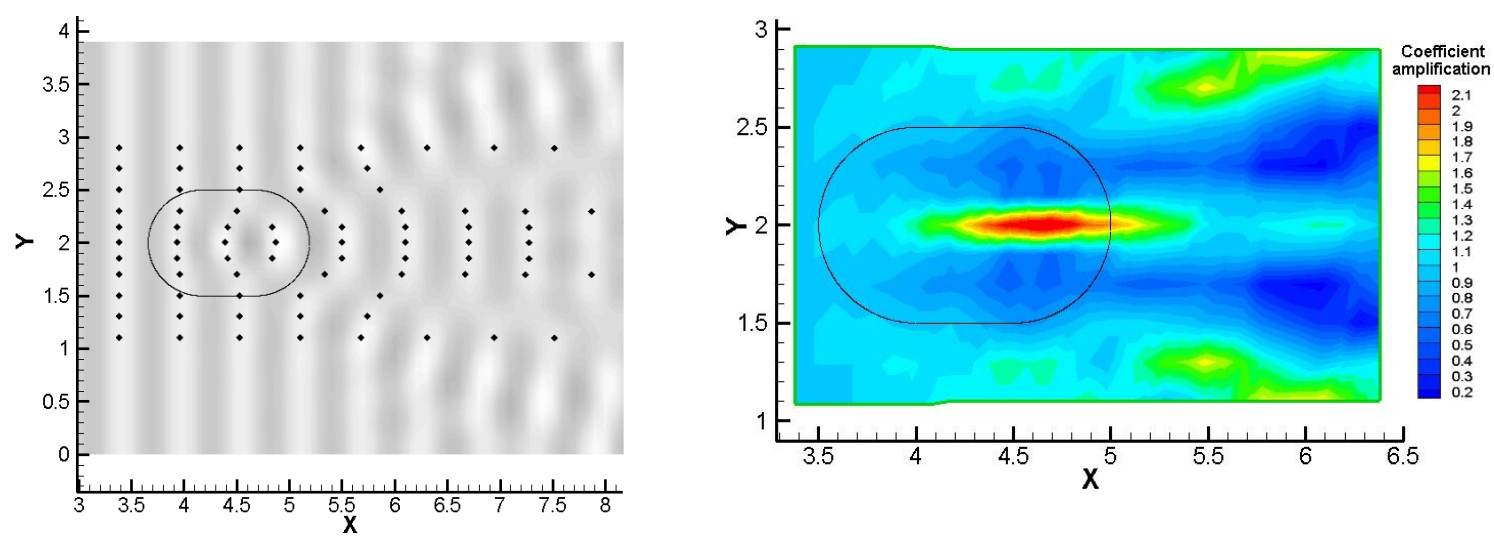

Fig. 10. Wave phase (left) and amplitude (right) measurements, $T=0.6 \mathrm{~s}$.

Table 4. Wave slopes along the y-axis.

\begin{tabular}{lcc}
\hline Run & Period & $\begin{array}{c}\text { Relative } \\
\text { wave slope }\end{array}$ \\
\hline 6 & $T=0.4$ & 0.62 \\
7 & $T=0.5$ & 1.30 \\
8 & $T=0.6$ & 2.33 \\
\hline
\end{tabular}

\section{Discussion and conclusion}

In the experiments presented above, we observed that not only the wave slope may be steep downstream of the shoal in the main wave direction, but also in the cross-section. In the following, the role of the diffraction in the wave crest evolution is presented and then discussed for the present experiment conditions.

\subsection{Role of the diffraction on the wave properties}

The potential associated to a progressive surface wave is given by:

$\phi(\mathrm{x}, \mathrm{y}, \mathrm{z}, t)=\Re e\left\{\frac{-i g}{2 \omega} \frac{c h(k(\mathrm{z}+h))}{c h(k h)} H e^{-i \omega t}\right\}$

where $H(\mathrm{x}, \mathrm{y}, \omega)$ the complex representation of the crestto-trough height of the surface elevation, $\omega$ the pulsation, $h(\mathrm{x}, \mathrm{y})$ the water depth, $g$ the gravity acceleration and $k$ the wave number given by the dispersion relation:

$k \tanh (k h)=\frac{\omega^{2}}{g}$

$H$ can be written

$H=\hat{H} e^{i S}$

where $\hat{H}(\mathrm{x}, \mathrm{y}, \omega)$ is the height envelope and $S(\mathrm{x}, \mathrm{y}, \omega)$ its phase. In the linear theory of surface gravity waves propagating over a mild sloping bottom, the equation of propagation is given by the mild-slope equation (Berkhoff, 1972):

$\operatorname{div}\left(C C_{\mathrm{g}} \overrightarrow{\operatorname{grad}} H\right)+k^{2} C C_{\mathrm{g}} H=0$

where $C=\omega / k$ is the phase celerity and $C_{\mathrm{g}}=\partial \omega / \partial k$ is the group velocity.

Taking the mild-slope equation, following the height envelope and phase, one obtains after the separation of real and imaginary parts:

$$
(\overrightarrow{\operatorname{grad}} S)^{2}=k^{2}+\frac{\operatorname{div}\left(C C_{\mathrm{g}} \overrightarrow{\operatorname{grad}} \hat{H}\right)}{C C_{\mathrm{g}} \hat{H}}
$$

and

$\operatorname{div}\left(C C_{\mathrm{g}} \hat{H}^{2} \overrightarrow{\operatorname{grad}} S\right)=0$

In the pure refraction case, where the amplitude variation is considered as negligible, Eq. (7) leads to the eikonal equation: $k=\overrightarrow{\operatorname{grad}} S$. When diffraction effect becomes preponderant, the second term of the right-hand side of Eq. (7) can not be neglected since $k$ cannot be directly assimilated to the wave number of a progressive wave. Writing

$k^{\prime}=\overrightarrow{\operatorname{grad}} S$

and introducing this relation in Eqs. (7) and (8), one obtains the following diffraction parameter (Holtuijsen and al., 2003):

$\delta_{H}=\frac{\operatorname{div}\left(C C_{\mathrm{g}} \overrightarrow{\operatorname{grad}} \hat{H}\right)}{k^{2} C C_{\mathrm{g}} \hat{H}}$

This parameter, which can be either positive or negative, indicates that in the presence of the diffraction effect, the 
wave number, the wave phase and group velocities are modified as follows:

$$
\left\{\begin{array}{l}
k^{\prime}=k \sqrt{1+\delta_{H}} \\
C^{\prime}=C / \sqrt{1+\delta_{H}} \\
C_{\mathrm{g}}^{\prime}=C_{\mathrm{g}} \sqrt{1+\delta_{H}}
\end{array}\right.
$$

where $k^{\prime}, C^{\prime}$ and $C_{\mathrm{g}}^{\prime}$ are, respectively, the modified wave number, phase and group velocities in the presence of diffraction.

\subsection{Application to the present case}

In the present case, the wave focuses at the top of the shoal, at the centre of the wave basin. Wave height amplification due to this focalization drives to diffraction effect that tends to distribute this focused energy on each side of the crest. In the present experiments, together with energy distribution due to the diffraction, a separation of phases is observed. Equation (11) show how diffraction plays a preponderant role in modifying waves characteristics compared to the refraction only. In order to quantify the real influence of the diffraction on the crest re-organization, we have to study the diffraction parameter behaviour along the wave propagation.

On the top of the shoal, crosswise wave height variations strongly increase. They are even more important crosswise than lengthwise for run 8 . Hence, we can assume that, at the cross-section located at $\mathrm{X}=5 \mathrm{~m}$ from the wave generator, the diffraction parameter varies on the same order than the second derivative of the $\mathrm{H}$ curve on that section:

$\delta_{H} \approx \Delta_{\mathrm{y}} H$

In Fig. 11a, the wave height $H$ in the section $X=5 \mathrm{~m}$ is superimposed to the diffraction parameter $\delta_{H}$ curve. The zone where the diffraction parameter is positive is presented in blue, the zone where it is negative in red. From Eq. (11), we notice that when the diffraction parameter is negative (in the red zone), the wave number decreases, which means that at this point of the crest, the wave length increases as well as the wave celerity. On the contrary, when the diffraction parameter is positive (in the blue zone), the wave length and the phase celerity decrease. This observation would tend to prove that diffraction increases the wave length where the amplification is the highest and decreases it on each side, in the purpose of straightening the crests to prevent wave crossing. In Fig. 11b, we can see that the crest is incurved backward and tends to cross and form a caustic, whereas, the crest straightens and becomes completely rectilinear because of the diffraction effect. Nevertheless, due to the fact that the line crest breaks suddenly above the shoal, line crests with opposite phases appear.

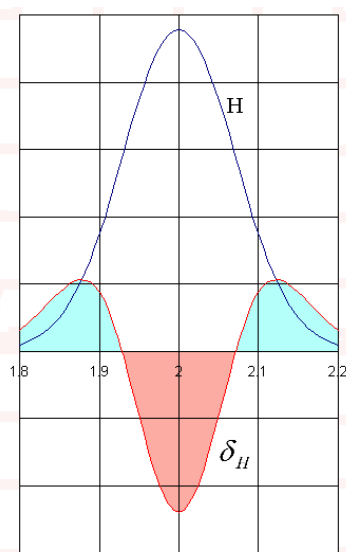

A

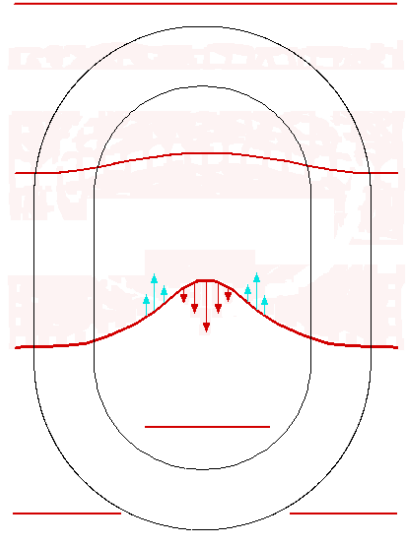

B
Fig. 11. (A) Evolution of the diffraction parameter $\delta_{H}$ with the wave height graph for the section located at $5 \mathrm{~m}$ from the wave generator, (B) Influence of the diffraction parameter $\delta_{H}$ on the crests organisation.

This discontinuity of phase along the crests lasts downstream of the shoal. This can be explained by the delay of the wave above the shoal of the order of half a wavelength of the incident wave.

In the Vincent and Briggs study, the phase delay due to the shoal is of the order of one wavelength, as mentioned by Jarry (2009). As a result, after a line crest break downstream the shoal, reorganization of the wave leads to a regular line crest with no more phase delay.

\subsection{Conclusions}

Results from the experiment performed in the wave basin for monochromatic water waves pointed out the shoal effect on wave steepening, both in the wave direction and in the crosssection. In particular, the presence of phase discontinuity along the crests enhances such a steepening. Besides this phenomenon, possibly at the origin of local extreme waves, wave propagation characteristics in the presence of the shoal have been carefully measured and may be of interest for the testing of numerical models. Investigations concerning the physical explanation of frequency depending on the opening angle of separation of the phases are in progress.

Edited by: E. Pelinovsky

Reviewed by: H. B. Branger and V. Maximov 


\section{References}

Arthur, R. S.: Refraction of water waves by islands and shoals with circular bottom contours, EOS T. Am. Geophys. Un., 27(2), p. $168,1946$.

Benoit, M., Marcos, F., and Becq, F.: Development of a thirdgeneration shallow-water wave model with unstructured spatial meshing, Proc. 25th Int. Conf. Coastal Eng. ASCE, New York, 465-478, 1996.

Berkhoff, J. C. W.: Computation of combined refraction-diffraction, Proc. 13th Coastal Eng. Conf., ASCE, New York, 471-490, 1972.

Berkhoff, J. C. W., Booy, N., and Radder, A. C.: Verification of numerical wave propagation models for simple harmonic linear water waves, Coast. Eng., 6(3), 255-279, 1982.

Booij, N., Ris, R. C., and Holthuijsen, L. H.: A third generation wave model for coastal regions, part I, model description and validation, J. Geophys. Res., 104, 7649-7666, 1999.

Holthuijsen, L. H., Herman, A., and Booij, N.: Phase-decoupled refraction-diffraction for spectral wave models, Coast. Eng., 49, 291-305, 2003.

Jarry, N.: Etudes expérimentales et numériques de la propagation des vagues au-dessus de bathymétries complexes en milieu côtier, Ph.D. thesis, Université du Sud Toulon-Var, 2009 (in French).
Kirby, J. T.: Higher order approximations in the parabolic equation method for water waves, J. Geophys. Res., 91, 933-952, 1986.

Kirby, J. T., Dalrymple, R. A., and Shi, F.: Combined refraction/diffraction model REF/DIF1, version 2.6. Documentation and User's Manual, Research Report No. CARC-02-02, Centre for Applied Coastal Research, Department of Civil and Environmental Engineering. University of Delaware, Newark, 2002.

Li, Y. S. and Zhan, J. M.: Boussinesq-type model with boundaryfitted coordinate system, J. Waterw. Div.-ASCE, New York, 127(3), 152-160, 2001.

Radder, A. C.: On the parabolic equation method for water-wave propagation, J. Fluid Mech., 95, 159-176, 1979.

Suh, K. D. and Dalrymple, R. A.: Application of angular spectrum model to simulation of irregular wave propagation, J. Waterw. Div.-ASCE, 119, 505-520, 1993.

Vincent, C. L. and Briggs, M. J.: Refraction-diffraction of irregular waves over a mound, J. Waterw. Div.-ASCE, 115, 269-284, 1989. 